\title{
Real-time changes in hippocampal energy demands during a spatial working memory task
}

\author{
John Kealy ${ }^{\mathrm{a}, \mathrm{b}, *}$, Rachel Bennett ${ }^{\mathrm{a}}$, Barbara Woods ${ }^{\mathrm{a}}$, John P. Lowry ${ }^{\mathrm{a}}$ \\ a Maynooth University Department of Chemistry, Maynooth University, Maynooth, Co. Kildare, Ireland \\ b Smurfit Institute of Genetics, Trinity College Dublin, Dublin 2, Ireland
}

\section{A R T I C L E I N F O}

\section{Article history:}

Received 15 December 2016

Received in revised form 18 February 2017

Accepted 21 February 2017

Available online 27 February 2017

\section{Keywords:}

Sensor

Biosensor

Hippocampus

Spatial memory

Glucose

Oxygen

\begin{abstract}
A B S T R A C T
Activity-dependent changes in hippocampal energy consumption have largely been determined using microdialysis. However, real-time recordings of brain energy consumption can be more accurately achieved using amperometric sensors, allowing for sensitive real-time monitoring of concentration changes. Here, we test the theory that systemic pre-treatment with glucose in rats prevents activity-dependent decreases in hippocampal glucose levels and thus enhances their performance in a spontaneous alternation task. Male Sprague Dawley rats were implanted into the hippocampus with either: 1) microdialysis probe; or 2) an oxygen sensor and glucose biosensor co-implanted together. Animals were pre-treated with either saline or glucose $(250 \mathrm{mg} / \mathrm{kg}) 30 \mathrm{~min}$ prior to performing a single 20min spontaneous alternation task in a +-maze. There were no significant differences found between either treatment group in terms of spontaneous alternation performance. Additionally, there was a significant difference found between treatment groups on hippocampal glucose levels measured using microdialysis (a decrease associated with glucose pre-treatment in control animals) but not amperometry. There were significant increases in hippocampal oxygen during +-maze exploration. Combining the findings from both methods, it appears that hippocampal activity in the spontaneous alternation task does not cause an increase in glucose consumption, despite an increase in regional cerebral blood flow (using oxygen supply as an index of blood flow) and, as such, pre-treatment with glucose does not enhance spontaneous alternation performance.
\end{abstract}

(c) 2017 Elsevier B.V. All rights reserved.

\section{Introduction}

Implantable sensors allow for stable, long-term recording of a number of common analytes found in the extracellular fluid (ECF) of the brain. Sensors have been developed that are sensitive to and selective for oxygen [1-4] and glucose [3,5-10], two correlates of increased neuronal activity. While sensors are limited in terms of what analytes can be measured at any one time, there are a number of advantages to electrochemical sensors over microdialysis, the current standard in measuring neurochemical changes in freely-moving animals. Their small size, high specificity, ability to record at a sub-second temporal resolution along with reduced levels of gliosis in surrounding tissue compared to microdialysis guide cannulae and probes [11,12] makes sensors an attractive

\footnotetext{
* Corresponding author at: Maynooth University Department of Chemistry, Maynooth University, Maynooth, Co. Kildare, Ireland.

E-mail address: kealyjo@tcd.ie (J. Kealy).
}

method for determining the relationships between neurochemistry, metabolism, neural activity and behaviour [13,14].

Tissue levels of oxygen in the brain can be accurately monitored in real time using electrochemical techniques such as constant potential amperometry that has been extensively characterised in the rat brain [15]. In particular, carbon paste electrodes (CPEs) have been shown to be able to detect concentrations of oxygen in the brain with high sensitivity and selectivity at a sub-second temporal resolution using constant potential amperometry [16]. Changes in the signal obtained from the CPE directly relate to changes in tissue oxygen levels, which are linked to regional cerebral blood flow [2]. As a translational tool, such sensors can be directly compared to changes in the blood oxygen level-dependent (BOLD) signal obtained using functional magnetic resonance imaging (fMRI) [17-21]. As with fMRI, differential changes in tissue oxygen concentrations can be used to functionally dissociate different regions of the brain [22]. As such, tissue oxygen levels measured using CPEs can then be used to assess the levels of neural activity in localised regions of the brain in freely-moving animals [23,24] including the hippocampus $[25,26]$. 
Similarly, changes in glucose concentration can also be monitored in real-time with high specificity and selectivity using constant potential amperometry, with biosensors incorporating glucose oxidase being the principal type of electrode used [6-8]. It has been determined that a platinum/poly $(0-$ phenylenediamine)/glucose oxidase (Pt/PPD/GOx) biosensor design allows for the best detection of glucose in vivo $[7,9,27]$ with real-time measurements of hippocampal glucose concentration now possible $[25,26]$. Previously, direct sampling of cerebrospinal fluid using microdialysis allowed for tissue concentrations of glucose to be determined [28] and for activity-related changes in glucose concentrations to be assessed [29-32]. However, all these studies have the drawback of poor temporal resolution with samples usually collected over the course of minutes meaning that fast changes in neurochemistry associated with individual behaviours may be missed. Higher temporal resolution detection is possible with recent advances in dialysate collection and analysis (up to $60 \mathrm{~s}$ ) but these techniques are still not approaching the real-time accuracy of amperometric sensors [33].

Due to the pivotal role the hippocampus plays in declarative memory [34-36], spatial navigation [37-39] and its links to various neurological disorders [40-44], it is vital to understand how activity in this region relates to function. Electrophysiological studies have created a wealth of data relating to neuronal activation and behaviour [45] but understanding the neurochemical underpinnings of behaviour, ranging from metabolism to signalling, has relied on either disruptive methods such as lesions, gene knock outs and pharmacological interventions $[46,47]$ or microdialysis, a technique poorly suited to looking at typical behavioural paradigms in rodents across short time spans as animals can solve tasks or perform multiple choices in less time than it takes to collect one microdialysis sample.

Focussing on energy consumption during behavioural tasks, the microdialysis literature has suggested that there are changes in hippocampal glucose concentration during performance in a spatial working memory task. Specifically, during a 20-min exploration of a +-maze, there is a significant decrease in hippocampal glucose compared to baseline levels [30,32]. Interestingly, McNay and colleagues [30] show that this activity-dependent decrease can be blocked by pre-treating the rats with a systemic injection of glucose with a corresponding enhancement of spontaneous alternation performance and that this activity-dependent decrease was restricted to the hippocampus for this particular spatial task [31]. Furthermore, age-related differences in spontaneous alternation performance and hippocampal glucose concentration have also been reported [48]. Pharmacological interventions can affect this activity-dependent decrease in hippocampal glucose; amyloid$\beta(1-42)$-induced impairment in the spontaneous alternation task is not accompanied by an activity-dependent decrease in hippocampal glucose [49]. Similarly, morphine-induced impairment in the same task is not accompanied by an activity-dependent decrease in hippocampal glucose even though the addition of exogenous glucose can reverse this impairment [50]. This suggests that neuronal activity in the hippocampus utilises extracellular glucose and that performance in the spontaneous alternation task can be improved if extracellular glucose levels are kept above a certain threshold.

These studies suggest a relatively straightforward relationship between hippocampal activity and hippocampal glucose concentration (with increased activity associated with decreases in glucose). However, as all these studies assume that hippocampal glucose concentration is usually around $1 \mathrm{mM}$ based on results from zero-net-flux experiments [51], which may be an overestimation of the baseline hippocampal glucose concentration. Indeed, recent work suggests that the concentration is lower, perhaps as low as around $0.60 \mathrm{mM}$ [25] or even $0.31 \mathrm{mM}$ [52], similar to levels esti- mated for the nucleus accumbens (0.54 mM; see [53] and [54]) and striatum $(0.35 \mathrm{mM}$; see [8]). Assuming a basal concentration of $1.00 \mathrm{mM}$ would therefore call into question any deviations from baseline glucose levels identified using the microdialysis method described in multiple studies [30-32,48]. There is also debate on the validity of microdialysis and zero-net-flux as trauma caused by implanting a microdialysis probe significantly alters the characteristics of the surrounding tissue [55], thus making the zero-net-flux approach less accurate than was previously appreciated [56-59].

Therefore, this study aims firstly to replicate the original microdialysis-based experiments looking at glucose pre-treatment in a spontaneous alternation task in the +-maze [30] by measuring activity-dependent changes in hippocampal glucose using microdialysis. A second experiment replaces the microdialysis probe with amperometric sensors: a CPE for measuring tissue oxygen in the hippocampus and a Pt/PPD/GOx biosensor for measuring hippocampal glucose. Correlation between the neurochemical data from both techniques and the behavioural data will be made as appropriate. If there is an activity-dependent decrease in hippocampal glucose concentration, we would expect to see it both using microdialysis and amperometric techniques. A cognitive enhancing effect for glucose pre-treatment should result in an attenuation of this activity-dependent decrease in hippocampal glucose and we expect both sampling techniques to show similar trends in any changes in glucose concentration. Finally, we can relate changes in hippocampal glucose concentration with changes in hippocampal oxygen consumption, a marker both of neuronal activity and of changes in regional cerebral blood flow.

\section{Materials and methods}

\subsection{Subjects}

Male Sprague Dawley rats (3 months old; 250-300 g; Charles River Laboratories International, Inc.; U.K.) were housed in a temperature-controlled facility with a 12-hour light/dark cycle (lights on at 07:00) with access ad libitum to food and water. All animals were handled for $5 \mathrm{~min}$ each day. All procedures were performed under license in accordance with the European Communities Regulations 2002 (Irish Statutory Instrument 566/2002).

\subsection{Data acquisition and statistical analysis}

All in vitro electrochemical experiments were performed using a low noise potentiostat (Biostat IV, ACM Instruments, Cumbria, U.K.). Data acquisition was performed using a PowerLab ${ }^{\circledR}$ interface system (ADInstruments Ltd., Oxford, U.K.) and a Logiq laptop. The software packages used were LabChart for Windows (Version 6) and EChem for Windows Version 1.5.2 (ADInstruments Ltd., Oxford, U.K.). For in vivo experiments, a four channel potentiostat was used (Quadstat, eDAQ Ltd., Australia). Digital acquisition was performed using an e-corder 821 system (eDAQ Ltd., Australia) and a Dell desktop PC. The software package used was Chart for Windows (Version 5, eDAQ Ltd., Australia).

All data was preliminarily processed in Microsoft ${ }^{\circledR}$ Excel $^{\circledR}$ for Mac 2011 (Version 14.2.2) before being exported to GraphPad Prism $^{\circledR} 5$ for Mac OS X (Version 5.0a) for statistical analysis and plotting of graphs. In the case of microdialysis samples, data was normalised to baseline levels. For recordings from sensors, all data was baseline-subtracted and area under curve (AUC) analysis was performed to quantify any observed changes in the sensor signals for statistical analysis. For multiple comparisons, repeatedmeasures and mixed-factorial analysis of variance tests (ANOVAs) with Bonferroni post hoc analysis were used as appropriate. Paired $t$-tests were also used when comparing results from two different 
time points. $p<0.05$ was considered to be significant and all data is presented as the mean \pm standard error of the mean (SEM).

\subsection{Working electrode preparation and surgery}

Carbon paste [60] was prepared by thoroughly mixing $0.71 \mathrm{~g}$ of graphite powder (1-2 $\mu \mathrm{m}$, Aldrich) with $250 \mu$ l of silicone oil (high temperature, Aldrich). CPEs were made from Teflon ${ }^{\circledR}$ coated silver wire $(8 \mathrm{~T}, 200 \mu \mathrm{m}$ bare diameter, $256 \mu \mathrm{m}$ coated diameter; Advent Research Materials, Suffolk, U.K.) as reported previously [2]. Pt/PPD/GOx sensors were made by immobilising GOx (from Aspergillus niger; EC 1.1.3.4, type VII-S; Sigma) in a poly (o-phenylenediamine) (PPD) film by potentiometric electropolymerisation of the monomer $o$-phenylenediamine (Sigma; $300 \mathrm{mmol} / \mathrm{l}$; see [61]) on the bare disc end of a freshly cut Teflon $^{\circledR}$-coated platinum wire $(5 \mathrm{~T}, 125 \mu \mathrm{m}$ bare diameter, $175 \mu \mathrm{m}$ coated diameter; Advent Research Materials, Suffolk, U.K.). A deoxygenated solution of the o-phenylenediamine monomer ( $300 \mathrm{mmol} / \mathrm{l}$ ) was prepared in $10 \mathrm{ml}$ phosphate buffered saline (PBS; pH 7.4; $0.15 \mathrm{M} \mathrm{NaCl}, 0.04 \mathrm{M} \mathrm{NaH}_{2} \mathrm{PO}_{4}$ and $0.04 \mathrm{M} \mathrm{NaOH}$; all from Sigma). An aliquot of $5 \mathrm{ml}$ of this solution was then added to a weighed quantity of GOx $(5 \mathrm{mg} / \mathrm{ml})$ and electropolymerised using constant potential amperometry at $+700 \mathrm{mV}$ versus a saturated calomel electrode as previously described [27].

Experiments to determine the sensitivity and selectivity for these sensor designs have previously been performed. CPEs are sensitive to changes in oxygen concentration and selective for oxygen over a range of interferent species $[15,16]$. Similarly, the $\mathrm{Pt} / \mathrm{PPD} / \mathrm{GOx}$ biosensor is sensitive to changes in glucose concentration and is selective for glucose over a range of interferent species $[7,9,27,62]$. In vitro calibrations were performed using constant potential amperometry in a standard three-electrode glass electrochemical cell containing $20 \mathrm{ml}$ PBS at room temperature. A saturated calomel electrode was used as the reference electrode and a bare platinum wire served as the auxiliary electrode. The applied potential for CPEs was $-650 \mathrm{mV}$ versus a saturated calomel electrode and for Pt/PPD/GOx electrodes was $+700 \mathrm{mV}$ versus a saturated calomel electrode. For $\mathrm{CPE} \mathrm{O}_{2}$ calibrations $(0-1200 \mu \mathrm{M})$ the PBS solution was vigorously purged with $\mathrm{O}_{2}$-free $\mathrm{N}_{2}$ (BOC Ireland, average $\mathrm{O}_{2}$ content 2 ppm, maximum $\mathrm{O}_{2}$ content $5 \mathrm{ppm}$ ) for at least 30 min to attain adequate deaeration of the PBS solution before recording. An $\mathrm{O}_{2}$ concentration of $240 \mu \mathrm{M}$ was obtained by bubbling atmospheric air using an air pump (RENA, U.S.A.) through the PBS for a minimum of 30 min $[63,64]$. Finally an $\mathrm{O}_{2}$ concentration of $1200 \mu \mathrm{M}$ was obtained by bubbling pure $\mathrm{O}_{2}$ gas (BOC Ireland) through the PBS for a minimum of 30 min $[63,65]$. For Pt/PPD/GOx glucose calibrations $(0-100 \mathrm{mM})$ aliquots of a $1 \mathrm{M}$ glucose stock solution were injected into the PBS solution in the cell. The PBS was briefly stirred using a magnetic stirring bead to uniformly mix the solution. Additionally, ascorbic acid calibrations $(0-100 \mu \mathrm{M})$ were performed in the same manner to confirm that there was minimal interference from ascorbic acid in vivo. The current was recorded throughout the course of each experiment and analysis was performed using quiescent steady-state conditions.

For sensor implantation, animals were anaesthetised using isoflurane (4\% in air for induction, $1.5-3.0 \%$ for maintenance; IsoFlo $^{\circledR}$, Abbott, U.K.) and placed in a stereotaxic frame. The skull was exposed and four anchor screws were implanted into the skull (one anchor screw doubling as the auxiliary electrode) and burr holes were made for the reference electrode and the working electrodes. The Pt/PPD/GOx biosensor was implanted into the hippocampus ( $-5.6 \mathrm{~mm}$ from Bregma, $+4.6 \mathrm{~mm}$ from midline, $5.1 \mathrm{~mm}$ from dorsal surface of brain; co-ordinates adapted from [32]). The CPE was implanted into the hippocampus in the same hemisphere $1.0 \mathrm{~mm}$ anterior to the Pt/PPD/GOx sensor. The reference electrode was implanted on the contralateral side of the brain using the same co-ordinates. The sensors were cemented into place using dental cement (Dentalon ${ }^{\circledR}$ Plus, Heraeus-Kulzer, Germany) and the gold connectors at the end of each electrode were inserted into a sixpin Teflon ${ }^{\circledR}$ socket (Plastics One, U.S.A.) which was also cemented in place. All animals were given saline $(0.9 \%)$ and analgesia (Buprecare $0.3 \mathrm{mg} / \mathrm{kg}$ body weight, AnimalCare Ltd., U.K.) and allowed to recover in an incubator. $24 \mathrm{~h}$ following recovery, animals were singly housed in a plastic home bowl in a temperature-controlled facility with a 12-hour light/dark cycle (lights on at 07:00) with access ad libitum to food and water.

\subsection{Microdialysis surgery}

For microdialysis guide cannula (CMA 12 guide cannulae CMA Microdialysis $A B$, Sweden) implantation, animals were anaesthetised using isoflurane (4\% in air for induction, $1.5-3.0 \%$ for maintenance; IsoFlo ${ }^{\circledR}$, Abbott, U.K.) and placed in a stereotaxic frame. The skull was exposed and three anchor screws were implanted into the skull and a burr hole was made for the guide cannula. The guide cannula was implanted into the hippocampus ( $-5.6 \mathrm{~mm}$ from Bregma, $+4.6 \mathrm{~mm}$ from midline, $3.6 \mathrm{~mm}$ from dorsal surface of brain; co-ordinates from [32]). The guide cannula was then cemented into place using dental cement (GC Fuji Plus capsules, GC United Kingdom Ltd., U.K.). All animals were given saline $(0.9 \%$ ) and analgesia (Buprecare $0.3 \mathrm{mg} / \mathrm{kg}$ body weight, AnimalCare Ltd., U.K.) and allowed to recover in an incubator. $24 \mathrm{~h}$ following recovery, animals were singly housed in a plastic home bowl in a temperature-controlled facility with a 12-hour light/dark cycle (lights on at 07:00) with access ad libitum to food and water.

\subsection{Behavioural apparatus}

The +-maze was constructed out of clear Perspex that was blacked out with adhesive plastic film on the exterior of the maze. The +-maze consisted of a central area connected to four arms ( $1 \mathrm{~m}$ in length) and mounted on a wooden table. Animals were also able to use visual cues around the room (support arm for tubing/electrode cables, notices on walls, etc.). A webcam was placed above the +-maze and videos of each trial were recorded using a PC in order to count the number and order of arm entries during the spontaneous alternation task.

For microdialysis experiments, all tubing was suspended using a pulley system above the home bowl and +-maze to allow the experimenter to lift the tubing out of the animals' way during exploration without interfering with the animal's movements. A liquid swivel (Instech Laboratories, Ltd., U.S.A.) was used to prevent the tubing from becoming tangled during exploration. For animals implanted with sensors, the headpiece from each animal was connected to the potentiostat via the six-pin Teflon ${ }^{\circledR}$ socket using a flexible screened six core cable (Plastics One, U.S.A.) through a multichannel commutator (Plastics One, U.S.A.) to prevent the cable from becoming tangled and to allow free movement of the animal in the bowl.

\subsection{Experimental procedure}

All injections were administered intraperitoneally (i.p.) $30 \mathrm{~min}$ prior to the animal entering the +-maze. Subjects were divided into two groups: 1) saline (0.9\%; $\mathrm{NaCl}$ from Sigma; $n=6)$; and 2) glucose $(250 \mathrm{mg} / \mathrm{kg}$; D-glucose from Sigma). Animals were weighed on each day and the respective doses for each animal were prepared immediately prior to injection. Stock solutions of glucose were allowed to stand for $24 \mathrm{~h}$ to allow the two enantiomers of the glucose molecule to come to equilibrium. A control group of animals (saline- and glucose-treated) that did not undergo any surgical implantation were used in order to determine whether tethered 
exploration (either with microdialysis or sensors) has an impact on performance in the +-maze.

For animals implanted with microdialysis guide cannulae, microdialysis probes (CMA 12 microdialysis probe; CMA Microdialysis $A B$, Sweden) were inserted into the hippocampus one week following surgery and $24 \mathrm{~h}$ prior to being put into the maze [30]. For at least 20 min prior to being placed in the +-maze and until at least 20 min following the +-maze, the microdialysis probes were perfused with artificial cerebrospinal fluid (aCSF; $128 \mathrm{mM}$ $\mathrm{NaCl} ; 3.0 \mathrm{mM} \mathrm{KCl} ; 1.3 \mathrm{mM} \mathrm{CaCl}_{2} ; 1.0 \mathrm{mM} \mathrm{MgCl}_{2} ; 21.0 \mathrm{mM} \mathrm{NaHCO}_{3}$; $1.3 \mathrm{mM} \mathrm{NaH}_{2} \mathrm{PO}_{4} ; 1.0 \mathrm{mM}$ D-glucose, $\mathrm{pH} \mathrm{7.0;} \mathrm{[30])} \mathrm{at} \mathrm{a} \mathrm{flow} \mathrm{rate} \mathrm{of}$ $1.0 \mu \mathrm{l} / \mathrm{min}$ using a mechanical syringe pump (Univentor Limited, Malta). Dialysate was collected over 5 min periods in collection vials (CMA Microdialysis AB, Sweden) and stored on ice before being transferred to a freezer $\left(-80^{\circ} \mathrm{C}\right) .12$ samples were collected from each animal: 4 samples from baseline period before being placed in the +-maze; 4 samples from exploration period in the +-maze; and 4 samples from post-baseline period after finishing the exploration session in the +-maze. Samples were later defrosted and glucose concentrations were determined using a CMA 600 clinical microdialysis analyser (CMA Microdialysis AB, Sweden). All values were normalised (baseline concentration $=100 \%$ ) for further analysis.

For animals implanted with sensors, animals were connected to the potentiostat $24 \mathrm{~h}$ prior to being put into the maze to allow time for the signal from the Pt/PPD/GOx biosensor to settle (CPEs usually settle within an hour). Sensor recordings were made at a sampling rate of $40 \mathrm{~Hz}$. In order to compare directly to the microdialysis data, the currents obtained from the sensors were normalised (baseline $=100 \%$ ) and $5 \mathrm{~min}$ time bins were used to make comparison with microdialysis easier. All other data is presented as real-time changes in current $(\mathrm{nA})$.

30 min following injection, each animal was transferred to the centre of the +-maze and allowed to explore freely for $20 \mathrm{~min}$. Arm entries were recorded by hand for all animals during the task and, for sensor implanted animals, all animal activity in the maze was also recorded in Chart (arm entries, arm exits, movement, rearing, grooming, etc.). Sessions were recorded using a webcam for post hoc assessment by another experimenter who was blind to the treatment. Treatment control groups for microdialysis and sensor experiments were given an intraperitoneal injection of saline or glucose but stayed in their home bowl instead of being placed in the +-maze.

Spontaneous alternation [30,66-68] was used as a measure of spatial working memory with animals visiting all 4 arms within any 5 -arm span of choices taken as a correct spontaneous alternation. 5-arm spans where animals do not visit all 4 arms were counted as incorrect alternations. Performance for each animal was determined by expressing the number of spontaneous alternations as a percentage of the total number of possible alternations. For example, if an animal enters the arms of the +-maze in the following order:

$1,3,4,2,3,1,3,2,4,2,1,4$

then we would analyse the data by taking 5 -arm spans that overlap and score it based on whether all four arms were visited in each span or not (a score of 1 or 0 respectively).

$\begin{array}{cc}1,3,4,2,3 & 1 \\ 3,4,2,3,1 & 1 \\ 4,2,3,1,3 & 1 \\ 2,3,1,3,2, & 0 \\ 3,1,3,2,4 & 1 \\ 1,3,2,4,2 & 1 \\ 3,2,4,2,1 & 1 \\ 2,4,2,1,4 & 0\end{array}$

In this example, this gives a score of 6 out of 8 potential alternations and is expressed as a percentage (75\%).

\section{Results}

\subsection{Effect of glucose pre-treatment on spontaneous alternation}

In this study, we failed to replicate the cognitive enhancement effect for glucose pre-treatment previously reported ([30]; Fig. 1). There were significant differences found in the number of arm entries observed in each group (Fig. 1A). Following a two-way ANOVA there were significant differences found for the number of arm entries based on treatment $(F=6.070 ; d f=1,27 ; p<0.05)$ and type of surgical implantation $(F=12.990 ; d f=2,27 ; p<0.001)$ but there was no significant interaction effect between treatment and surgical implantation $(F=1.421 ; d f=2,27 ; p>0.05)$. Glucose treatment seemed to result in an increased numbers of arm entries across all surgical conditions but Bonferroni post hoc analysis showed no significant differences for treatment within any of the three surgical conditions (no surgery controls, sensors and microdialysis). A one-way ANOVA confirmed that there were significant differences in arm entries based on the type of surgical implantation $(F=9.866 ; d f=2,14 ; p<0.01)$ with Bonferroni post hoc analysis showing that animals implanted with sensors performed significantly fewer arm entries compared to the no surgery controls $(p<0.01)$. There were no other significant differences between the surgical implantation groups.

With respect to the potential for glucose pre-treatment to enhance spatial working memory in the spontaneous alternation task, we failed to find any significant effects for treatment on performance (Fig. 1B). Following a two-way ANOVA there was no significant difference found in spontaneous alternation scores based on treatment $(F=0.196 ; d f=1,27 ; p>0.05)$ or type of surgical implantation $(F=0.707 ; d f=2,27 ; p>0.05)$ and there was no significant interaction effect $(F=1.421 ; d f=2,27 ; p>0.05)$, confirming that pre-treatment with glucose had no effect on spatial working memory in this task.

In order to determine whether differences in performance were due to treatment-induced changes in locomotor activity, the number of arm entries was correlated with the percentage of correct spontaneous alternations. There were no significant correlations found between locomotor activity and performance following saline or glucose treatment in no surgery control rats (Fig. 1C), sensor-implanted rats (Fig. 1D), or microdialysis probe-implanted rats (Fig. 1E).

\subsection{Changes in hippocampal glucose during spontaneous alternation measured using microdialysis}

Changes in hippocampal glucose and lactate were analysed across three 20-minute time periods (baseline; +-maze exploration; post-exploration) with $4 \times 5$ min dialysate samples collected in each time period. All data was normalised to baseline levels before statistical analysis. During the control condition where animals stay in their home bowl (Figs. 2A), a two-way repeated measures ANOVA showed that there was a significant effect for treatment on hippocampal glucose $(F=8.320 ; d f=1,77 ; p<0.05)$ but there were no significant effects for time $(F=1.152 ; d f=11$, $77 ; p>0.05)$ nor was there an interaction effect $(F=1.760 ; d f=11$, $77 ; p>0.05)$. Bonferroni post hoc analysis showed that hippocampal glucose levels were significantly lower in the glucose-treated group in sample number $9(0-5 \mathrm{~min}$ into the post-baseline period; $p<0.01)$.

During +-maze exploration (Figs. 2B), a two-way repeated measures ANOVA showed that there was no significant effect for treatment on hippocampal glucose $(F=3.342 ; d f=1,88 ; p>0.05)$ but there was a significant effect for time $(F=2.209$; $d f=11,88$; $p<0.01)$ as well as a significant interaction effect $(F=2.276 ; d f=11$, $88 ; p<0.01)$. Bonferroni post hoc analysis showed that hippocampal 


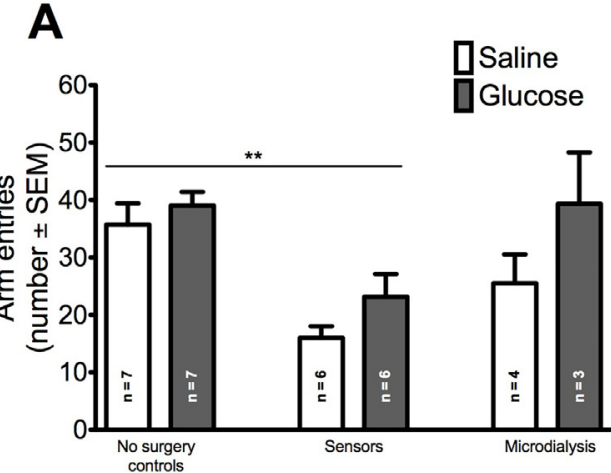

C

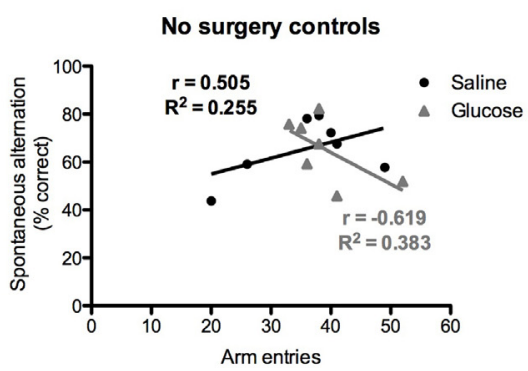

B

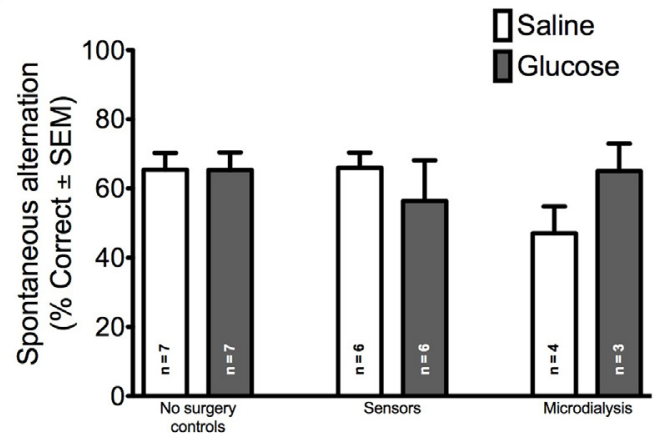

$\mathbf{E}$
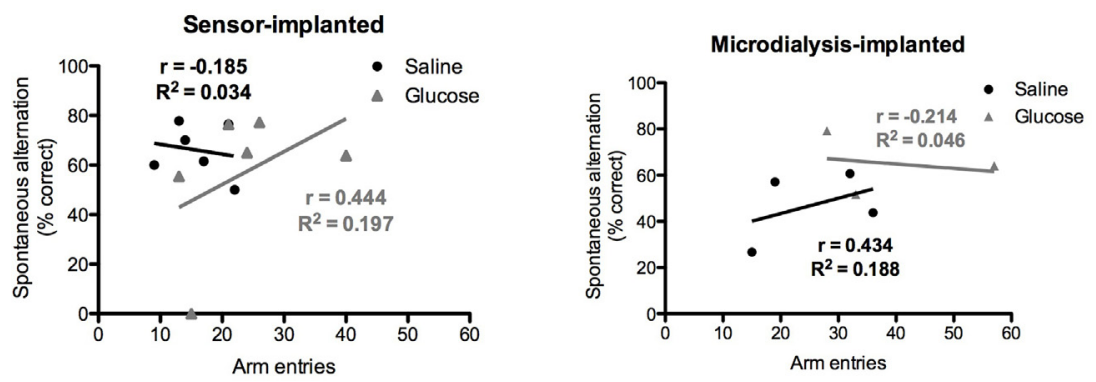

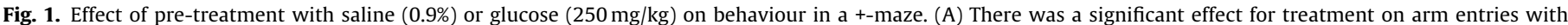

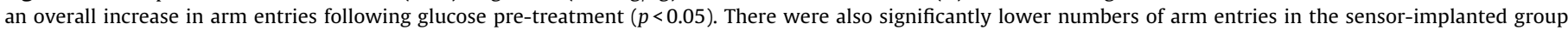

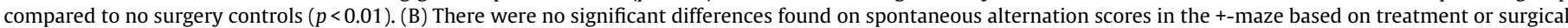

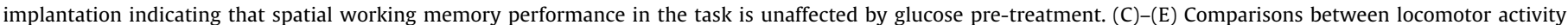

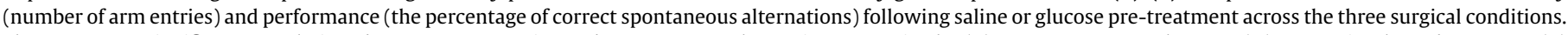

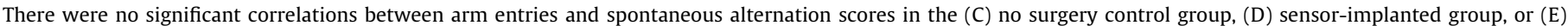
microdialysis-implanted group. ${ }^{* *} p<0.01$.

glucose levels were significantly lower in the glucose-treated group in sample number 10 (5-10 min into the post-baseline period).

Comparison of hippocampal glucose levels using AUC analysis (Fig. 2C) following a two-way ANOVA showed that there was a significant effect for treatment $(F=5.323 ; d f=1,15 ; p<0.05)$ but there were no significant effects for behavioural condition (home bowl control versus +-maze exploration; $F=2.142 ; d f=1,15 ; p>0.05$ ) or for interaction $(F=1.233 ; d f=1,15 ; p>0.05)$. Bonferroni post hoc analysis did not reveal any further significant effects but there was a non-significant trend of a decrease in hippocampal glucose following glucose treatment in the control condition.

\subsection{Changes in hippocampal glucose and oxygen during spontaneous alternation measured using amperometric sensors}

Real-time changes in hippocampal glucose (using the Pt/PPD/GOx biosensor) and oxygen (using the CPE) were analysed across three time periods ( 20 min baseline; $20 \mathrm{~min}+-$ maze exploration; 20 min post-exploration) and all data was baselinesubtracted to allow for direct comparison between animals. As animals were tethered to the potentiostat for $24 \mathrm{~h}$ prior to the experiment in order to obtain a stable glucose baseline, it was possible to look at the effect of saline and glucose injections on the glucose and oxygen signals. There were few differences visible in the average raw traces in the control condition aside from short-term changes associated with injection stress (Fig. 2D and $2 \mathrm{G}$ ). However, changes in hippocampal oxygen were evident in the first few minutes of maze exploration (Fig. $2 \mathrm{H}$ ) but no noticeable changes in hippocampal glucose were observed during maze exploration (Fig. 2E).

AUC analysis was initially performed on the sensor signals from the control groups by taking the 10 min period immediately before the injection (Baseline) and comparing that to a 10 min period $30 \mathrm{~min}$ after the injection ( $+30 \mathrm{~min})$. A two-way ANOVA on the AUC data for hippocampal glucose (Fig. 3A) showed no significant effect for either treatment $(F=4.015 ; d f=1,26 ; p>0.05)$ or time $(F=0.028$; $d f=1,26 ; p>0.05)$ and there was no interaction effect between these two factors $(F=0.021 ; d f=1,26 ; p>0.05)$. Similarly, a twoway ANOVA on the AUC data for hippocampal oxygen (Fig. 3D) showed no significant effect for treatment $(F=0.782 ; d f=1,26$; $p>0.05)$, time $(F=0.013 ; d f=1,26 ; p>0.05)$ or interaction effect $(F=0.001 ; d f=1,26 ; p>0.05)$.

AUC analysis on the effect of +-maze exploration was then investigated. Data was baseline-subtracted to remove variance from individual animals in each condition. For hippocampal glucose (Fig. 2F), a two-way ANOVA showed that there were no significant effects for behavioural condition $(F=0.229$; $d f=1,23$; $p>0.05)$, treatment $(F=3.099 ; d f=1,23 ; p>0.05)$ or for interaction $(F=0.735 ; d f=1,23 ; p>0.05)$. For hippocampal oxygen (Fig. $2 \mathrm{I})$, a two-way ANOVA revealed that there were significant effects for behavioural condition $(F=12.480 ; d f=1,22 ; p<0.01)$ and for treatment $(F=5.866 ; d f=1,22 ; p<0.05)$ but there was no interaction effect $(F=1.111 ; d f=1,22 ; p>0.05)$. Bonferroni post hoc analysis revealed that there was a significant increase in hippocampal oxygen in the saline-treated group when comparing +-maze exploration to the home bowl control condition $(p<0.01)$. There was a similar increase in hippocampal oxygen during the +-maze following glucose treatment but this did not reach significance $(p>0.05)$.

By combining sensor recordings with behavioural data, it is possible to compare the AUC values for +-maze exploration in hippocampal glucose and oxygen to locomotor activity (arm entries) and to spatial working memory (percentage of correct spontaneous alterations). There were no significant correlations between AUC values for hippocampal glucose in either treatment condition with 
A

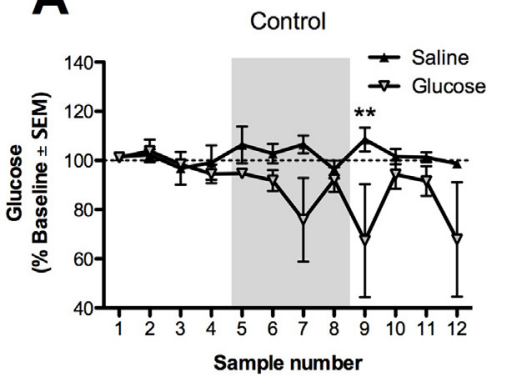

D

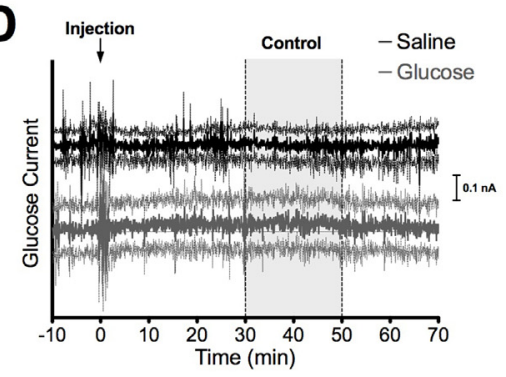

G

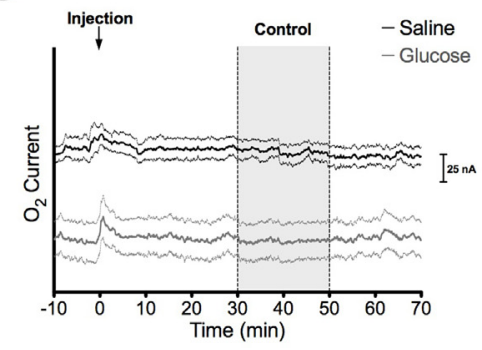

B

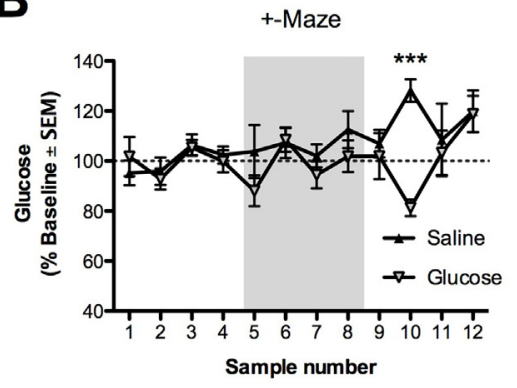

E

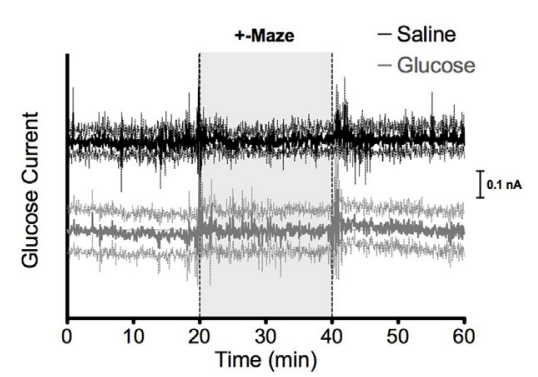

H

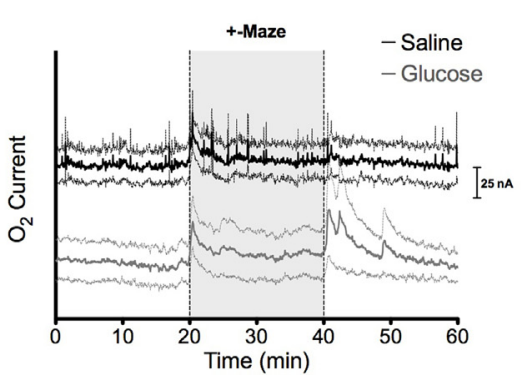

C
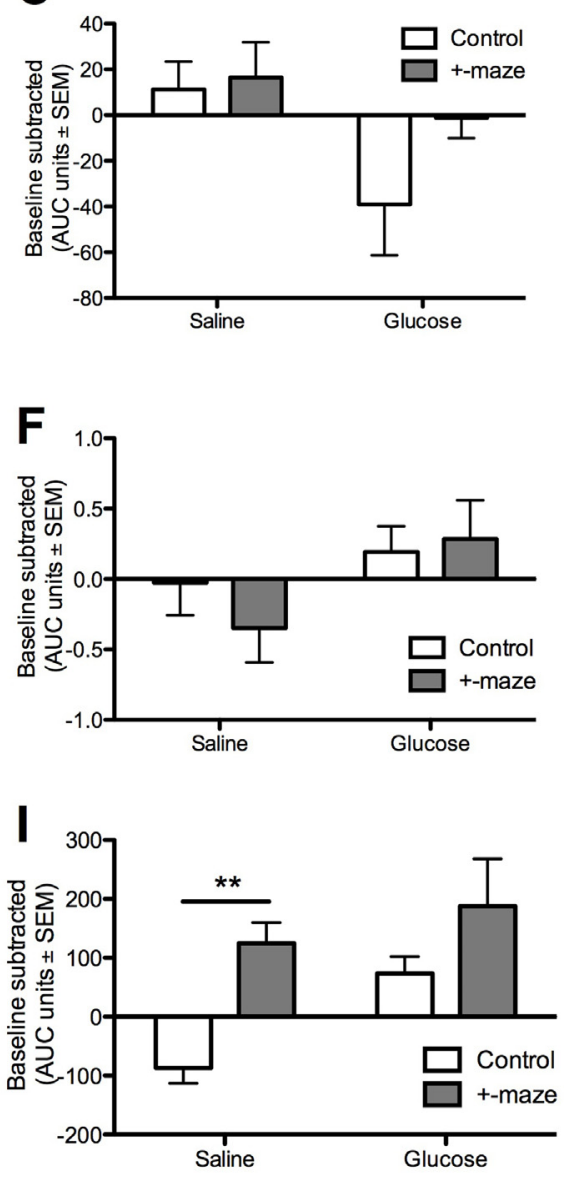

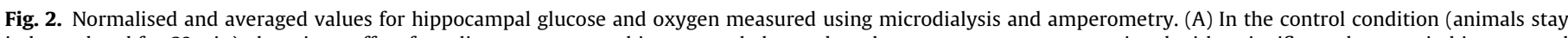

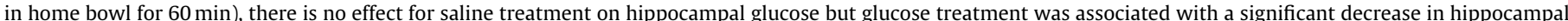

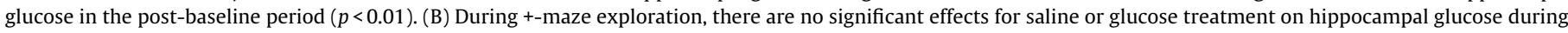

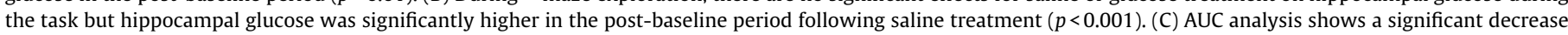

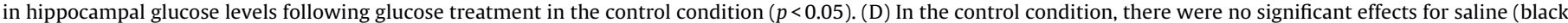

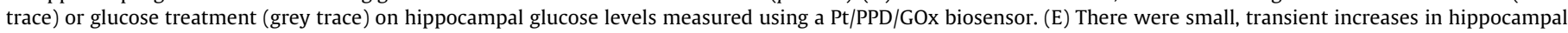

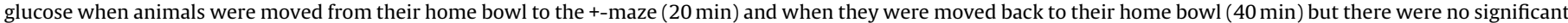

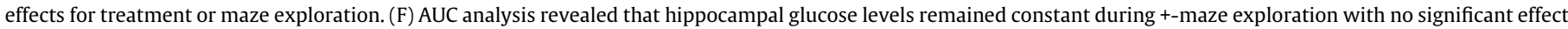

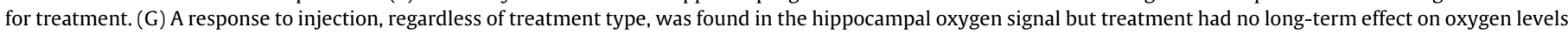

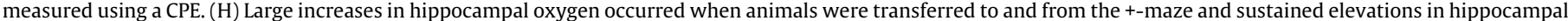

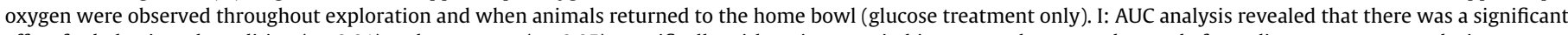

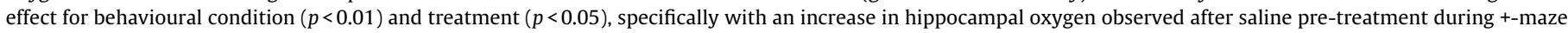
exploration $(p<0.01){ }^{* *} p<0.01$.

locomotor activity (Fig. 3B) or spatial working memory (Fig. 3C). Similarly, there were no significant correlations between AUC values for hippocampal oxygen in either treatment condition with locomotor activity (Fig. 3E) or spatial working memory (Fig. 3F). However, there did appear to be a trend for glucose treatment to be associated with a moderate negative correlation between hippocampal glucose and locomotor activity $\left(r=-0.652 ; R^{2}=0.425\right)$ and a moderate positive correlation between hippocampal oxygen and locomotor activity $\left(r=0.654 ; R^{2}=0.423\right)$.

\section{Discussion}

The data presented in this paper failed to replicate either the behavioural effects of glucose administration on spatial working memory or find an activity-dependent decrease in hippocampal glucose during +-maze exploration using microdialysis and amperometric sensors as described elsewhere in the literature $[30,32,48]$. However, activity-dependent changes in hippocampal glucose and oxygen were found though these changes might be associated with locomotor activity rather than spatial working memory. The data presented here reinforces the growing body of evidence that suggests that microdialysis measurements based on the zero net flux method may be flawed and that the assumption that basal hippocampal glucose levels are as high as $1 \mathrm{mM}$ [51] may be incorrect [25]. Additionally, the data presented here supports our argument that microsensors are a more suitable method for measuring changes in neurochemistry related to behaviour - as well as offering real-time recordings over long periods of time [25,26], allowing for functional dissociation of tissue based on neurochemical changes $[22,69]$, and reducing tissue induced injury $[11,12,55]$, sensors such as the ones employed here are also easier to use in a behavioural task (no loose tubing or need for a pulley system) and can allow for neurochemical and electrophysiological recordings to be made simultaneously [70].

Regarding the effects of glucose on spatial working memory, it was expected pre-treatment with an intraperitoneal injection of glucose would enhance performance on the spontaneous alternation task, a measure of spatial working memory [71]. Previously, 


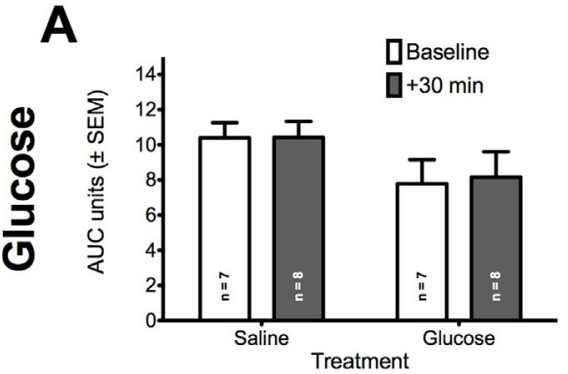

B

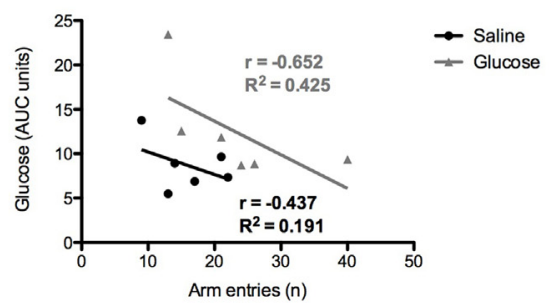

$\mathbf{E}$

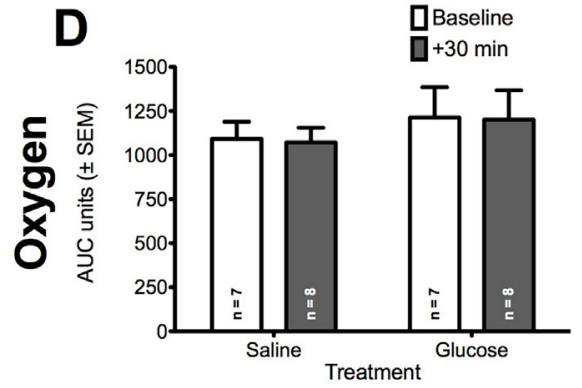

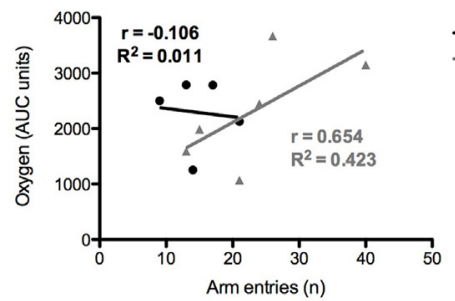

C

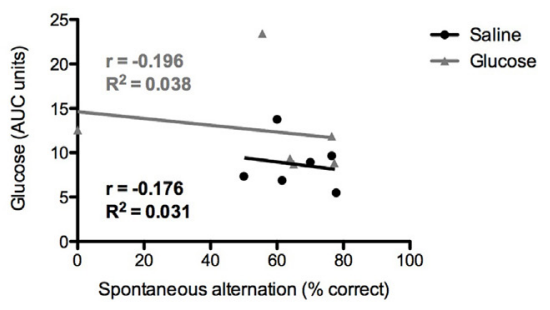

$\mathbf{F}$

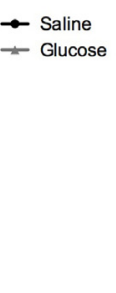

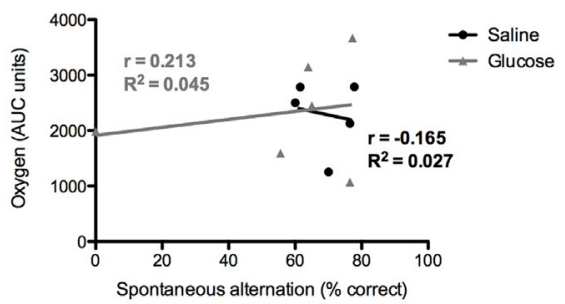

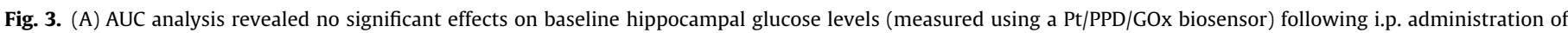

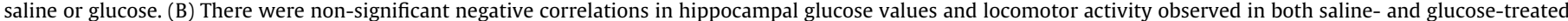

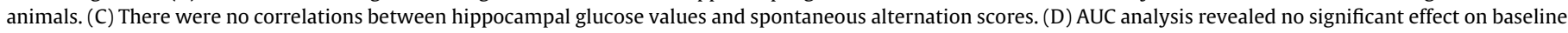

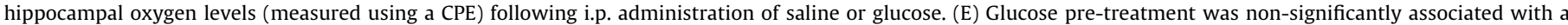

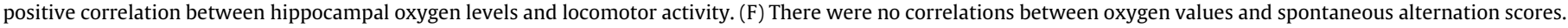

it has been shown that pre-treatment with glucose significantly increases spontaneous alternation scores in 3 months old Sprague Dawley rats [30]. This finding was replicated in both 3 month old and aged rats [48] though the wider literature suggests that young rats should be performing at close to full cognitive capacity; pretreatment with glucose has been shown to have no significant effect on conditional discrimination learning [72] and a marginal effect on radial arm maze performance in young rats [73]. The data presented above supports this idea as our 3 month old Sprague Dawley rats performed similarly whether pre-treated with saline or glucose (Fig. 1). The only effect that could be put down to glucose pre-treatment was an increase in locomotor activity (i.e. the number of arm entries) but this was a subtle effect and no correlations between increased locomotor activity and alternation score was found. Furthermore, it has been shown in other hippocampal-dependent tasks that glucose pre-treatment needs to be administered $2-3 \mathrm{~h}$ ahead of behavioural testing [74] versus the 30 min pre-treatment used in the bulk of the spontaneous alternation studies. Though it must be noted that spontaneous alternation is sensitive to the extent to which there are extra-maze cues available to the animals [75]; it could be the case that there were more cues available in our laboratory compared to other groups, thus making it easier for animals to navigate the +-maze.

Along with treatment, the effect of different surgical implantations was also investigated. There was a trend towards lower numbers of arm entries in the groups with sensors and microdialysis probes implanted. Additionally, three animals were not included in the results as they failed to explore entirely (though appeared normal in their home cage), all three were implanted with microdialysis probes, possibly indicating slightly less freedom of movement compared to other conditions or reduced motivation to explore. However, as there was no significant effect on task performance between the surgical groups, we are confident that behavioural measurements in these groups remain valid. The one caveat is that such large environments may not be best suited to using a tethered system (either microdialysis or sensors) and smaller arenas or operant chamber-style behavioural tasks might be more suited to these methods [18,19,21,69].

The second expected finding was for hippocampal glucose levels to decrease as cognitive demand increased [30,32]. In this study, we failed to detect an activity-related decrease in hippocampal glucose using microdialysis (Fig. 2B and C) or the glucose biosensor (Fig. 2E and F). Disparities between microdialysis and biosensor recordings of glucose were expected based on our previous estimates of hippocampal glucose concentrations [25] and due to the increased disruption of tissue around microdialysis probes [55]. Yet, in this case neither method showed a clear decrease in hippocampal glucose in relation to the task. This could be due to the relative ease of the task having little impact on hippocampal energy consumption; although the hippocampus has been shown to be required for alternation tasks [76,77], it appears to be more necessary for longterm alternation memory than for short-term versions of the task [78] and other regions such as the medial prefrontal cortex may be more pertinent to working spatial memory [79-81].

It is also worth noting that peripheral administration of glucose did not impact on basal levels of hippocampal glucose measured using the biosensor beyond the transient changes associated with injection stress (Fig. 2D). However, we did observe a non-significant decrease in hippocampal glucose in the control condition in microdialysis-(Fig. 2A and C), this was unexpected and goes against previous work that has shown that peripheral administration of glucose does not directly affect glucose levels in the brain $[7,82]$. We believe that given that the decrease was non-significant and the large standard error (in each case due to an outlier at those time points in different animals) that this is an artefact of the microdialysis technique.

Interestingly, there appears to be a non-significant increase in hippocampal glucose measured using microdialysis during and after the spontaneous alternation task (Figs. 2B and C) and any changes in hippocampal glucose appear to be unrelated to performance in the spontaneous alternation task (Fig. 3C). Overall, this is the opposite of what has been previously reported in the literature $[48,83]$. Although the spontaneous alternation task appears 
to engage the hippocampus, as evidenced by the increase in tissue oxygen (a marker of regional cerebral blood flow), this working memory task does not appear to tax the energy needs of the hippocampus in terms of glucose consumption.

Another issue to consider is that most studies using microdialysis need to target more ventral regions of the hippocampus in order to accommodate the size of the probe (as was replicated in the present study). The ventral hippocampus plays a greater role in affective processes than it does in spatial memory (which is largely processed by the dorsal hippocampus). This is consistent with findings from the ventral hippocampus during the elevated plus maze (a measure of anxiety-related behaviour); exposure to the elevated plus maze is associated with only a transient decrease in hippocampal glucose measured using microdialysis [84] and there is a functional dissociation of the dorsal and ventral hippocampus observed during spatial and anxiety tasks using oxygen sensors [22].

In contrast to performance, there was an overall trend in the behavioural data for an increase in arm entries for glucosetreated animals. Glucose treatment also appears to interact with hippocampal glucose (negative correlation with locomotor activity) and oxygen (positive correlation with locomotor activity). These findings are tentative at best but may be a parsimonious explanation for the activity-dependent decreases in hippocampal glucose reported by other groups; increased locomotor activity may decrease glucose in the hippocampus rather than the decrease being due to an increased spatial working memory load. This would fit with the suggestion that the spontaneous alternation task is not a good model of working or short-term memory so care should be taken in interpreting behavioural data from any pharmacological interventions using it as an index of working memory [67].

\section{Conclusions}

The present study challenges the assumptions that pretreatment with a systemic injection of glucose can enhance spatial working memory performance by reversing an activity-induced decrease in hippocampal glucose. Instead, we find that although the hippocampus shows clear activation during the task (as evidenced by increases in hippocampal oxygen), the cognitive demand that this enacts on the hippocampus is not sufficient to significantly alter hippocampal glucose concentrations.

\section{Acknowledgements}

The authors would like to thank Mr. Noel Williams and Dr. Kenneth Pierce for their assistance in constructing the +-maze and microdialysis sampling apparatus. This research was made possible by funding provided by Enterprise Ireland (PC/2009/523 and CP/2011/0103) co-funded by the European Regional Development Fund, NUI Maynooth (John and Pat Hume Scholarship) and the Centre of Applied Science for Health which is funded by the Higher Education Authority under the Programme for Research in Third Level Institutions (PRTLI) Cycle 4. The authors have no conflict of interest to disclose.

\section{References}

[1] J.P. Lowry, M.G. Boutelle, R.D. O’Neill, M. Fillenz, Characterization of carbon paste electrodes in vitro for simultaneous amperometric measurement of changes in oxygen and ascorbic acid concentrations in vivo, Analyst 121 (6) (1996) 761-766, https://www.ncbi.nlm.nih.gov/pubmed/8763205.

[2] J.P. Lowry, M.G. Boutelle, M. Fillenz, Measurement of brain tissue oxygen at a carbon past electrode can serve as an index of increases in regional cerebral blood flow, J. Neurosci. Methods 71 (2) (1997) 177-182, https://www.ncbi.nlm.nih.gov/pubmed/9128153.

[3] J.P. Lowry, M. Fillenz, Real-time monitoring of brain energy metabolism in vivo using microelectrochemical sensors: the effects of anesthesia,
Bioelectrochemistry 54 (1) (2001) 39-47,

https://www.ncbi.nlm.nih.gov/pubmed/11506973.

[4] F.B. Bolger, J.P. Lowry, Brain Tissue Oxygen at a carbon past electrode can serve as an index of increases in regional cerebral blood flow, J. Neurosci. Methods 5 (11) (2005) 473-487.

[5] M. Fillenz, J.P. Lowry, Studies of the source of glucose in the extracellular compartment of the rat brain, Dev. Neurosci. 20 (4-5) (1998) 365-368, https://www.ncbi.nlm.nih.gov/pubmed/9778573.

[6] J.P. Lowry, M. Demestre, M. Fillenz, Relation between cerebral blood flow and extracellular glucose in rat striatum during mild hypoxia and hyperoxia, Dev. Neurosci. 20 (1) (1998) 52-58,

https://www.ncbi.nlm.nih.gov/pubmed/9600390.

[7] J.P. Lowry, M. Miele, R.D. O’Neill, M.G. Boutelle, M. Fillenz, An amperometric glucose-oxidase/poly(o-phenylenediamine) biosensor for monitoring brain extracellular glucose: in vivo characterisation in the striatum of freely-moving rats, J. Neurosci. Methods 79 (1) (1998) 65-74, https://www.ncbi.nlm.nih.gov/pubmed/9531461.

[8] J.P. Lowry, R.D. O’Neill, M.G. Boutelle, M. Fillenz, Continuous monitoring of extracellular glucose concentrations in the striatum of freely moving rats with an implanted glucose biosensor, J. Neurochem. 70 (1) (1998) 391-396, https://www.ncbi.nlm.nih.gov/pubmed/9422386.

[9] B.M. Dixon, J.P. Lowry, R.D. O'Neill, Characterization in vitro and in vivo of the oxygen dependence of an enzyme/polymer biosensor for monitoring brain glucose, J. Neurosci. Methods 119 (2) (2002) 135-142, https://www ncbi.nlm nih gov/pubmed/12323417.

[10] Y. Hu, G.S. Wilson, Rapid changes in local extracellular rat brain glucose observed with an in vivo glucose sensor, J. Neurochem. 68 (4)(1997) 1745-1752, https://www.ncbi.nlm.nih.gov/pubmed/9084449.

[11] P.M. Bungay, P. Newton-Vinson, W. Isele, P.A. Garris, J.B. Justice, Microdialysis of dopamine interpreted with quantitative model incorporating probe implantation trauma, J. Neurochem. 86 (4) (2003) 932-946, https://www.ncbi.nlm.nih.gov/pubmed/12887691.

[12] L.M. Borland, G. Shi, H. Yang, A.C. Michael, Voltammetric study of extracellular dopamine near microdialysis probes acutely implanted in the striatum of the anesthetized rat, J. Neurosci. Methods 146 (2) (2005) 149-158, https://www.ncbi.nlm.nih.gov/pubmed/15975664.

[13] J.P. Lowry, R.D. O’Neill, Neuroanalytical chemistry in vivo using electrochemical sensors, in: C.A. Grimes, E.C. Dickey, M.V. Pishko (Eds.), Encyclopedia of Sensors, American Scientific Publishers, U.S.A, 2006, pp. 1-23.

[14] L.A. Newman, D.L. Korol, P.E. Gold, Lactate produced by glycogenolysis in astrocytes regulates memory processing, PLoS One 6 (12) (2011) e28427, https://www.ncbi.nlm.nih.gov/pubmed/22180782.

[15] F.B. Bolger, R. Bennett, J.P. Lowry, An in vitro characterisation comparing carbon paste and Pt microelectrodes for real-time detection of brain tissue oxygen, Analyst 136 (19) (2011) 4028-4035, https://www.ncbi.nlm.nih.gov/pubmed/21804983.

[16] F.B. Bolger, S.B. McHugh, R. Bennett, J. Li, K. Ishiwari, J. Francois, M.W. Conway, G. Gilmour, D.M. Bannerman, M. Fillenz, M. Tricklebank, J.P. Lowry, Characterisation of carbon paste electrodes for real-time amperometric monitoring of brain tissue oxygen, J. Neurosci. Methods 195 (2) (2011) 135-142, https://www.ncbi.nlm.nih.gov/pubmed/21115045.

[17] J.P. Lowry, K. Griffin, S.B. McHugh, A.S. Lowe, M. Tricklebank, N.R. Sibson, Real-time electrochemical monitoring of brain tissue oxygen: a surrogate for functional magnetic resonance imaging in rodents, Neuroimage 52 (2) (2010) 549-555, https://www.ncbi.nlm.nih.gov/pubmed/20417284.

[18] J. Francois, M.W. Conway, J.P. Lowry, M.D. Tricklebank, G. Gilmour, Changes in reward-related signals in the rat nucleus accumbens measured by in vivo oxygen amperometry are consistent with fMRI BOLD responses in man, Neuroimage 60 (4) (2012) 2169-2181, https://www.ncbi.nlm.nih.gov/pubmed/22361256

[19] J. Francois, J. Huxter, M.W. Conway, J.P. Lowry, M.D. Tricklebank, G. Gilmour, Differential contributions of infralimbic prefrontal cortex and nucleus accumbens during reward-based learning and extinction, J. Neurosci. 34 (2) (2014) 596-607, https://www.ncbi.nlm.nih.gov/pubmed/24403158.

[20] J. Li, K. Ishiwari, M.W. Conway, J. Francois, J. Huxter, J.P. Lowry, A.J. Schwarz, M. Tricklebank, G. Gilmour, Dissociable effects of antipsychotics on ketamine-induced changes in regional oxygenation and inter-regional coherence of low frequency oxygen fluctuations in the rat, Neuropsychopharmacology 39 (7) (2014) 1635-1644, https://www.ncbi.nlm.nih.gov/pubmed/24442094.

[21] J. Francois, O. Grimm, A.J. Schwarz, J. Schweiger, L. Haller, C. Risterucci, A Bohringer, Z. Zang, H. Tost, G. Gilmour, A. Meyer-Lindenberg, Ketamine suppresses the ventral striatal response to reward anticipation: a cross-species translational neuroimaging Study, Neuropsychopharmacology 41 (5) (2016) 1386-1394, https://www.ncbi.nlm.nih.gov/pubmed/26388147.

[22] S.B. McHugh, M. Fillenz, J.P. Lowry, J.N. Rawlins, D.M. Bannerman, Brain tissue oxygen amperometry in behaving rats demonstrates functional dissociation of dorsal and ventral hippocampus during spatial processing and anxiety, Eur. J. Neurosci. 33 (2) (2011) 322-337, https://www.ncbi.nlm.nih.gov/pubmed/21105915.

[23] J. Li, D.S. Bravo, A.L. Upton, G. Gilmour, M.D. Tricklebank, M. Fillenz, C. Martin, J.P. Lowry, D.M. Bannerman, S.B. McHugh, Close temporal coupling of neuronal activity and tissue oxygen responses in rodent whisker barrel cortex, Eur. J. Neurosci. 34 (12) (2011) 1983-1996, https://www.ncbi.nlm.nih.gov/pubmed/22151136. 
[24] D.M. Russell, E.M. Garry, A.J. Taberner, C.J. Barrett, J.F. Paton, D.M. Budgett, S.C. Malpas, A fully implantable telemetry system for the chronic monitoring of brain tissue oxygen in freely moving rats, J. Neurosci. Methods 204 (2) (2012) 242-248, https://www.ncbi.nlm.nih.gov/pubmed/22123353.

[25] J. Kealy, R. Bennett, J.P. Lowry, Simultaneous recording of hippocampal oxygen and glucose in real time using constant potential amperometry in the freely-moving rat, J. Neurosci. Methods 215 (1) (2013) 110-120, https://www.ncbi.nlm.nih.gov/pubmed/23499196.

[26] J. Kealy, R. Bennett, J.P. Lowry, Real-time effects of insulin-induced hypoglycaemia on hippocampal glucose and oxygen, Brain Res. 1598 (2015) 76-87, https://www.ncbi.nlm.nih.gov/pubmed/25511995.

[27] J.P. Lowry, K. McAteer, S.S. El Atrash, A. Duff, R.D. O'Neill, Characterization of glucose oxidase-modified poly(phenylenediamine)-coated electrodes in vitro and in vivo: Homogeneous interference by ascorbic acid in hydrogen peroxide detection, Anal. Chem. 66 (1994) 1754-1761.

[28] M. Sandberg, S.P. Butcher, H. Hagberg, Extracellular overflow of neuroactive amino acids during severe insulin-induced hypoglycemia: in vivo dialysis of the rat hippocampus, J. Neurochem. 47 (1) (1986) 178-184, https://www.ncbi.nlm.nih.gov/pubmed/3519869.

[29] L.K. Fellows, M.G. Boutelle, M. Fillenz, Extracellular brain glucose levels reflect local neuronal activity: a microdialysis study in awake, freely moving rats, J. Neurochem. 59 (6) (1992) 2141-2147, https://www.ncbi.nlm.nih.gov/pubmed/1431898.

[30] E.C. McNay, T.M. Fries, P.E. Gold, Decreases in rat extracellular hippocampal glucose concentration associated with cognitive demand during a spatial task, Proc. Natl. Acad. Sci. U. S. A. 97 (6) (2000) 2881-2885, https://www.ncbi.nlm.nih.gov/pubmed/10706633.

[31] E.C. McNay, R.C. McCarty, P.E. Gold, Fluctuations in brain glucose concentration during behavioral testing: dissociations between brain areas and between brain and blood, Neurobiol. Learn. Mem. 75 (3) (2001) 325-337, https://www.ncbi.nlm.nih.gov/pubmed/11300738.

[32] D. De Bundel, I. Smolders, R. Yang, A.L. Albiston, Y. Michotte, S.Y. Chai, Angiotensin IV and LVV-haemorphin 7 enhance spatial working memory in rats: effects on hippocampal glucose levels and blood flow, Neurobiol. Learn. Mem. 92 (1) (2009) 19-26, https://www.ncbi.nlm.nih.gov/pubmed/19233301.

[33] A. Morales-Villagran, R. Beltran-Ramirez, S.J. Lopez-Perez, V. Palomera-Avalos, L. Medina-Ceja, A capillary fraction collector coupled to a fluorescence reader: a novel device to continuously quantify glutamate during microdialysis, Neurochem. Res. 37 (7) (2012) 1457-1464, https://www.ncbi.nlm.nih.gov/pubmed/22399331.

[34] W.B. Scoville, B. Milner, Loss of recent memory after bilateral hippocampal lesions, J. Neurol. Neurosurg. Psychiatry 20 (1) (1957) 11-21, https://www.ncbi.nlm.nih.gov/pubmed/13406589.

[35] N.J. Cohen, J. Ryan, C. Hunt, L. Romine, T. Wszalek, C. Nash, Hippocampal system and declarative (relational) memory: summarizing the data from functional neuroimaging studies, Hippocampus 9 (1) (1999) 83-98, https://www.ncbi.nlm.nih.gov/pubmed/10088903.

[36] M.J. Eacott, A. Easton, Episodic memory in animals: remembering which occasion, Neuropsychologia 48 (8) (2010) 2273-2280, https://www.ncbi.nlm.nih.gov/pubmed/19913043.

[37] J. O'Keefe, L. Nadel, The Hippocampus as a Cognitive Map, Oxford University Press, U.K, 1978

[38] R.G. Morris, P. Garrud, J.N. Rawlins, J. O'Keefe, Place navigation impaired in rats with hippocampal lesions, Nature 297 (5868) (1982) 681-683, https://www.ncbi.nlm.nih.gov/pubmed/7088155.

[39] R. D'Hooge, P.P. De Deyn, Applications of the Morris water maze in the study of learning and memory, Brain Res. Brain Res. Rev. 36 (1) (2001) 60-90, https://www.ncbi.nlm.nih.gov/pubmed/11516773.

[40] S. Heckers, C. Konradi, Hippocampal pathology in schizophrenia, Curr. Top. Behav. Neurosci. 4 (2010) 529-553, https://www.ncbi.nlm.nih.gov/pubmed/21312412

[41] M.W. Marlatt, P.J. Lucassen, Neurogenesis and Alzheimer's disease: Biology and pathophysiology in mice and men, Curr. Alzheimer Res. 7 (2) (2010) 113-125, https://www.ncbi.nlm.nih.gov/pubmed/19860727.

[42] T. Bast, The hippocampal learning-behavior translation and the functional significance of hippocampal dysfunction in schizophrenia, Curr. Opin. Neurobiol. 21 (3) (2011) 492-501, https://www.ncbi.nlm.nih.gov/pubmed/21330132.

[43] V. Dhikav, K. Anand, Potential predictors of hippocampal atrophy in Alzheimer's disease, Drugs Aging 28 (1) (2011) 1-11, https://www.ncbi.nlm.nih.gov/pubmed/21174483.

[44] L. Bonilha, G.U. Martz, S.S. Glazier, J.C. Edwards, Subtypes of medial temporal lobe epilepsy: influence on temporal lobectomy outcomes? Epilepsia 53 (1) (2012) 1-6, https://www.ncbi.nlm.nih.gov/pubmed/22050314.

[45] J. O'Keefe, Hippocampal neurophysiology in the behaving animal, in: R. Morris, D. Amaral, T. Bliss, J. O'Keefe (Eds.), in The Hippocampus Book, Oxford University Press, Oxford, 2007, pp. 475-548.

[46] D.M. Bannerman, J.N. Rawlins, M.A. Good, The drugs don't work-or do they? Pharmacological and transgenic studies of the contribution of NMDA and GluR-A-containing AMPA receptors to hippocampal-dependent memory, Psychopharmacology (Berl) 188 (4) (2006) 552-566, https://www.ncbi.nlm.nih.gov/pubmed/16676163.

[47] S.J. Martin, R.E. Clark, The rodent hippocampus and spatial memory: from synapses to systems, Cell. Mol. Life Sci. 64 (4) (2007) 401-431, https://www.ncbi.nlm.nih.gov/pubmed/17256090.
[48] E.C. McNay, P.E. Gold, Age-related differences in hippocampal extracellular fluid glucose concentration during behavioral testing and following systemic glucose administration, J. Gerontol. A. Biol. Sci. Med. Sci. 56 (2) (2001) B66-B71, https://www.ncbi.nlm.nih.gov/pubmed/11213269.

[49] J. Pearson-Leary, E.C. McNay, Intrahippocampal administration of amyloid-beta(1-42) oligomers acutely impairs spatial working memory, insulin signaling, and hippocampal metabolism, J. Alzheimers Dis. 30 (2) (2012) 413-422, https://www.ncbi.nlm.nih.gov/pubmed/22430529.

[50] E.C. McNay, C.E. Canal, R.S. Sherwin, P.E. Gold, Modulation of memory with septal injections of morphine and glucose: effects on extracellular glucose levels in the hippocampus, Physiol. Behav. 87 (2) (2006) 298-303. https://www.ncbi.nlm.nih.gov/pubmed/16343563.

[51] E.C. McNay, P.E. Gold, Extracellular glucose concentrations in the rat hippocampus measured by zero-net-flux: effects of microdialysis flow rate, strain, and age, J. Neurochem. 72 (2) (1999) 785-790, https://www.ncbi.nlm.nih.gov/pubmed/9930754.

[52] C. Stein, J. Hopfeld, H. Lau, J. Klein, Effects of Ginkgo biloba Extract EGb 761, Donepezil and their Combination on Central Cholinergic Function in Aged Rats, J. Pharm. Pharm. Sci. 18 (4) (2015) 634-646, https://www.ncbi.nlm.nih.gov/pubmed/26626253.

[53] E.A. Kiyatkin, M. Lenoir, Rapid fluctuations in extracellular brain glucose levels induced by natural arousing stimuli and intravenous cocaine: fueling the brain during neural activation, J. Neurophysiol. 108 (6) (2012) 1669-1684, https://www.ncbi.nlm.nih.gov/pubmed/22723672.

[54] R.A. Bola, E.A. Kiyatkin, Robust Brain Hyperglycemia during General Anesthesia: Relationships with Metabolic Brain Inhibition and Vasodilation, Front. Physiol. 7 (2016) 39, https://www.ncbi.nlm.nih.gov/pubmed/26913008.

[55] A.S. Khan, A.C. Michael, Invasive consequences of using micro-electrodes and microdialysis probes in the brain, Trends Anal. Chem. 22 (2003) 503-508.

[56] K.C. Chen, Insensitivity of the microdialysis zero-net-flux method to nonlinear uptake and release processes, Neurosci. Res. 46 (2) (2003) 251-256, https://www.ncbi.nlm.nih.gov/pubmed/12767488.

[57] K.C. Chen, Evidence on extracellular dopamine level in rat striatum: implications for the validity of quantitative microdialysis, J. Neurochem. 92 (1) (2005) 46-58, https://www.ncbi.nlm.nih.gov/pubmed/15606895.

[58] K.C. Chen, Preferentially impaired neurotransmitter release sites not their discreteness compromise the validity of microdialysis zero-net-flux method, J. Neurochem. 92 (1) (2005) 29-45, https://www.ncbi.nlm.nih.gov/pubmed/15606894.

[59] K.C. Chen, Effects of tissue trauma on the characteristics of microdialysis zero-net-flux method sampling neurotransmitters, J. Theor. Biol. 238 (4) (2006) 863-881, https://www.ncbi.nlm.nih.gov/pubmed/16129452.

[60] R.D. O'Neill, R.A. Grunewald, M. Fillenz, W.J. Albery, Linear sweep voltammetry with carbon paste electrodes in the rat striatum, Neuroscience 7 (8) (1982) 1945-1954, https://www.ncbi.nlm.nih.gov/pubmed/6127652.

[61] R.J. Geise, J.M. Adams, N.J. Barone, A.M. Yacynych, Electropolymerized films to prevent interferences and electrode fouling in biosensors, Biosens. Bioelectron. 6 (1991) 151-160.

[62] J.P. Lowry, R.D. O'Neill, Partial characterization in vitro of glucose oxidase-modified poly(phenylenediamine)-coated electrodes for neurochemical analysis in vivo, Electroanalysis 6 (1994) 369-379.

[63] C. Bourdillon, V. Thomas, D. Thomas, Electrochemical study of D-glucose oxidase autoinactivation, Enzyme Microb. Technol. 4 (1982) 175-180.

[64] T.H. Foster, D.F. Hartley, M.G. Nichols, R. Hilf, Fluence rate effects in photodynamic therapy of multicell tumor spheroids, Cancer Res. 53 (6) (1993) 1249-1254, https://www.ncbi.nlm.nih.gov/pubmed/8443805.

[65] G. Bazzu, G.G. Puggioni, S. Dedola, G. Calia, G. Rocchitta, R. Migheli, M.S. Desole, J.P. Lowry, R.D. O'Neill, P.A. Serra, Real-time monitoring of brain tissue oxygen using a miniaturized biotelemetric device implanted in freely moving rats, Anal. Chem. 81 (6) (2009) 2235-2241, https://www.ncbi.nlm.nih.gov/pubmed/19222224.

[66] E.C. McNay, P.E. Gold, Memory modulation across neural systems: intra-amygdala glucose reverses deficits caused by intraseptal morphine on a spatial task but not on an aversive task, J. Neurosci. 18 (10)(1998) 3853-3858, https://www.ncbi.nlm.nih.gov/pubmed/9570814

[67] R.N. Hughes, The value of spontaneous alternation behavior (SAB) as a test of retention in pharmacological investigations of memory, Neurosci. Biobehav. Rev. 28 (5) (2004) 497-505, https://www.ncbi.nlm.nih.gov/pubmed/15465137.

[68] C.T. Johnson, D.S. Olton, F.H. Gage III, P.G. Jenko, Damage to hippocampus and hippocampal connections: effects on DRL and spontaneous alternation, J. Comp. Physiol. Psychol. 91 (3) (1977) 508-522, https://www.ncbi.nlm.nih.gov/pubmed/874119.

[69] S.B. McHugh, C. Barkus, A. Huber, L. Capitao, J. Lima, J.P. Lowry, D.M. Bannerman, Aversive prediction error signals in the amygdala, J. Neurosci. 34 (27) (2014) 9024-9033, https://www.ncbi.nlm.nih.gov/pubmed/24990922.

[70] J. Kealy, S. Commins, J.P. Lowry, The effect of NMDA-R antagonism on simultaneously acquired local field potentials and tissue oxygen levels in the brains of freely-moving rats, Neuropharmacology 116 (2017) 343-350, https://www.ncbi.nlm.nih.gov/pubmed/28087359.

[71] M.R. Stefani, G.M. Nicholson, P.E. Gold, ATP-sensitive potassium channel blockade enhances spontaneous alternation performance in the rat: a potential mechanism for glucose-mediated memory enhancement, Neuroscience 93 (2) (1999) 557-563, https://www.ncbi.nlm.nih.gov/pubmed/10465439. 
[72] G. Winocur, Glucose-enhanced performance by aged rats on a test of conditional discrimination learning, Psychobiology 23 (1995) 270-276.

[73] G. Winocur, S. Gagnon, Glucose treatment attenuates spatial learning and memory deficits of aged rats on tests of hippocampal function, Neurobiol. Aging 19 (3) (1998) 233-241, https://www.ncbi.nlm.nih.gov/pubmed/9661998.

[74] A.J. Li, Y. Oomura, K. Sasaki, K. Suzuki, I. Tooyama, K. Hanai, H. Kimura, T. Hori, A single pre-training glucose injection induces memory facilitation in rodents performing various tasks: contribution of acidic fibroblast growth factor, Neuroscience 85 (3) (1998) 785-794,

https://www.ncbi.nlm.nih.gov/pubmed/9639272.

[75] R.C. Lennartz, The role of extramaze cues in spontaneous alternation in a plus-maze, Learn. Behav. 36 (2) (2008) 138-144, https://www.ncbi.nlm.nih.gov/pubmed/18543713.

[76] R. Lalonde, The neurobiological basis of spontaneous alternation, Neurosci. Biobehav. Rev. 26 (1) (2002) 91-104, https://www.ncbi.nlm.nih.gov/pubmed/11835987.

[77] G.M. Dillon, X. Qu, J.N. Marcus, J.C. Dodart, Excitotoxic lesions restricted to the dorsal CA1 field of the hippocampus impair spatial memory and extinction learning in C57BL/6 mice, Neurobiol. Learn. Mem. 90 (2) (2008) 426-433, https://www.ncbi.nlm.nih.gov/pubmed/18602845.

[78] A. Isseroff, Limited recovery of spontaneous alternation after extensive hippocampal damage: evidence for a memory impairment, Exp. Neurol. 64 (2) (1979) 284-294, https://www.ncbi.nlm.nih.gov/pubmed/428506.
[79] N. Hidaka, K. Suemaru, K. Takechi, B. Li, H. Araki, Inhibitory effects of valproate on impairment of Y-maze alternation behavior induced by repeated electroconvulsive seizures and c-Fos protein levels in rat brains, Acta Med. Okayama 65 (4) (2011) 269-277, https://www.ncbi.nlm.nih.gov/pubmed/21860534.

[80] J. Gotesson, M. Ericson, B. Soderpalm, C. Pickering, Repeated ethanol but not phencyclidine impairs spontaneous alternation behaviour in the Y-maze, Basic Clin. Pharmacol. Toxicol. 110 (4) (2012) 347-352 https://www.ncbi.nlm.nih.gov/pubmed/22004516.

[81] S.T. Yang, Y. Shi, Q. Wang, J.Y. Peng, B.M. Li, Neuronal representation of working memory in the medial prefrontal cortex of rats, Mol. Brain 7 (2014) 61, https://www.ncbi.nlm.nih.gov/pubmed/25159295.

[82] M.G. Boutelle, C. Stanford, M. Fillenz, W.J. Albery, P.N. Bartlett, An amperometric enzyme electrode for monitoring brain glucose in the freely moving rat, Neurosci. Lett. 72 (3) (1986) 283-288, https://www.ncbi.nlm.nih.gov/pubmed/3547181.

[83] E.C. McNay, R.S. Sherwin, Effect of recurrent hypoglycemia on spatial cognition and cognitive metabolism in normal and diabetic rats, Diabetes 53 (2) (2004) 418-425, https://www.ncbi.nlm.nih.gov/pubmed/14747293.

[84] A. Rex, B. Bert, H. Fink, J.P. Voigt, Stimulus-dependent changes of extracellular glucose in the rat hippocampus determined by in vivo microdialysis, Physiol. Behav. 98 (4) (2009) 467-473, https://www.ncbi.nlm.nih.gov/pubmed/19660483. 